\title{
CONTRIBUTION TO THE KNOWLEDGE OF GEMINOPPIA (ACARI, ORIBATIDA, OPPIIDAE), WITH DESCRIPTION OF A NEW SPECIES FROM SOUTH AFRICA
}

\author{
Sergey G. Ermilov ${ }^{1 *}$, Elizabeth A. Hugo-Coetzeie ${ }^{2,3}$ and Alexander A. Khaustov ${ }^{1}$ \\ ${ }^{1}$ Tyumen State University, Institute of Environmental and Agricultural Biology (X-BIO) \\ Lenina str. 25, 625000 Tyumen, Russia; corresponding author \\ E-mail:ermilovacari@yandex.ru; https://orcid.org/0000-0002-0913-131X \\ E-mail: alex1973khaustov@gmail.com; https://orcid.org/0000-0002-0306-112X \\ ${ }^{2}$ National Museum, 36 Aliwal St., 9301 Bloemfontein, South Africa \\ ${ }^{3}$ University of the Free State, 205 Nelson Mandela Dr., Park West, 9301, Bloemfontein, South Africa \\ E-mail: lhugo@nasmus.co.za; https://orcid.org/0000-0003-0525-9049
}

A new species of the genus Geminoppia (Oribatida, Oppiidae) is described from moss of Hogsback State Forest, Eastern Cape Province, South Africa. Geminoppia amatholensis sp. n. differs from its related species Geminoppia maior comb. $\mathbf{n}$. by the absence of discidium and the presence of very long notogastral seta $h_{1}$. Summarized generic traits, an identification key, distribution and habitats of all known species of Geminoppia are presented.

Key words: Oribatida, new species, oppiid mites, taxonomy, morphology, Afrotropical region, Geminoppia.

\section{INTRODUCTION}

The genus Geminoppia (Acari, Oribatida, Oppiidae) was proposed by J. Balogh and P. BAlogh (1983) with Geminoppia papineaui J. Balogh et P. Balogh, 1983 as type species. Later, two species, Tectoppiella ansifera Mahunka, $1985 b$ and Globoppia velata Franklin et Woas, 1992, were combined with and included in Geminoppia (Subías \& Balogh 1989, Subías 2004). Thus, currently the genus comprises three species having a highly circumscribed geographic distribution: G. ansifera is endemic to South Africa, G. papineaui endemic to New Caledonia and G. velata endemic to Brazil (Subías 2020).

During taxonomic identification of oribatid mites from Hogsback State Forest in South Africa, we found a new species belonging to Geminoppia. The main goals of our paper are: to describe and illustrate this new species based on adults; to summarize the generic morphological traits; to provide an identification key to known species of Geminoppia; to present data on distribution and habitats of representatives of the genus. In addition, we discuss the systematic placement of Globoppia maior Hammer, 1962(a) with the idea of transferring it into Geminoppia. 


\section{MATERIAL AND METHODS}

Substrate sample (moss on unknown tree) containing oribatid mites were collected $\left(250 \mathrm{~cm}^{3}\right)$ in Hogsback State Forest, a centuries-old indigenous Afromontane forest near the village of Hogsback ( $\left.32^{\circ} 35^{\prime} S, 2^{\circ} 57^{\prime} \mathrm{E}\right)$, situated in the Amathole mountains, Eastern Cape Province, South Africa (see also Mucina \& Geldenhurs 2006). Mites were extracted from samples into $75 \%$ ethanol using Berlese's funnels with electric lamps in laboratory conditions for five days.

Specimens were mounted in lactic acid on temporary cavity slides for measurement and illustration. Body length was measured in lateral view, from the tip of the rostrum to the posterior edge of the notogaster. Notogastral width refers to the maximum width of the notogaster in dorsal view. Lengths of body setae were measured in lateral aspect. All body measurements are presented in micrometres. Formulas for leg setation are given in parentheses according to the sequence trochanter-femur-genu-tibia-tarsus (famulus included). Formulas for leg solenidia are given in square brackets according to the sequence genu-tibia-tarsus.

Drawings were made with a camera lucida using a Leica transmission light microscope “Leica DM 2500". Images were obtained with an AxioCam ICc3 camera using a Carl Zeiss transmission light microscope "Axio Lab.A1".

Morphological terminology used in this paper follows that of F. Grandjean: see Travé and VACHON (1975) for references; NorTON (1977) for leg setal nomenclature; and NorTON and Behan-Pelletier (2009) for an overview.

The following abbreviations are used (including text, figures and table): Integument: $r o f=$ rostral foveola; $m t u=$ microtubercle; $t u=$ tubercle. Prodorsum: $r o, l e, i n, b s, e x=$ rostral, lamellar, interlamellar, bothridial, and exobothridial setae, respectively; exv = vestige of second exobothridial seta; $b o=$ bothridium; $m s=$ muscle sigilla. Notogaster: $c, l a, l m, l p, h, p=$ notogastral setae; $i a, i m$, ip, ih, ips = notogastral lyrifissures; gla = opisthonotal gland opening; $c s=$ circumgastric scissure. Gnathosoma: $a, m, h=$ subcapitular setae; or = adoral seta; $d$, $l$, sup, inf, $c m, u l, s u l, v t, l t=$ palp setae; $\omega=$ palp solenidion; $c h a, c h b=$ cheliceral setae; $T g=$ Trägårdh's organ. Epimeral and lateral podosomal regions: ap2, apsj = apodeme II and sejugal apodeme, respectively; $a b 4=$ apodemal border IV; $1 a-c, 2 a, 3 a-c, 4 a-c=$ epimeral setae; $p c a=$ parietal carina; $I=$ pedotectum I. Anogenital region: $G P=$ genital plate; $A P=$ anal plate; $g$, $a g$, an, ad = genital, aggenital, anal, and adanal setae, respectively; $i a d$ = adanal lyrifissure; po = preanal organ. Legs: $\mathrm{Tr}, \mathrm{Fe}, \mathrm{Ge}, \mathrm{Ti}, \mathrm{Ta}=$ leg trochanter, femur, genu, tibia, tarsus, respectively; $t r t=$ trochanteral tooth; $\omega, \phi, \sigma=$ leg solenidia; $\varepsilon=$ leg famulus; $d, l, v, b v, e v, f t, t c, i t$, $p, u, a, s, p v, p l=$ leg setae; $p a=$ porose area.

\section{SYSTEMATICS \\ Family Oppiidae}

Genus Geminoppia J. Balogh et P. Balogh, 1983

Type species: Geminoppia papineaui Balogh et P. Balogh, 1983

\section{Main generic traits of Geminoppia}

Adult. Size. Medium size, length about 330-620. Prodorsum. Rostrum rounded or tripartite. Costula and transcostula usually absent, rarely form- 
ing small semi-oval complex. Interbothridial and postbothridial tubercles not observed. Two or three pairs of interbothridial muscle sigillae observed. Rostral and lamellar setae of medium length, interlamellar and exobothridial setae short, all setiform. Bothridial seta clavate, with longer stalk and shorter, rounded distally head. Notogaster. Without humeral tooth and crista. With reduced number of notogastral setae in $h$-row: usually nine pairs (exceptionally six pairs*) of setiform setae, $c$ present, minute or represented by alveolus, $h_{3}$ completely absent. Dorsal setae located in two longitudinal parallel rows (la anteriorly or anterolaterally to $\mathrm{lm}$ ), usually some of them clearly longer than other setae. Gnathosoma. Subcapitulum diarthric. Adoral seta present. Solenidion located in distal part of palp, connected with distal seta. Chelicera chelate-dentate. Epimeral and lateral podosomal regions. Epimeral border IV present, semi-oval. Epimeral setal formula: 3-1-3-3. All setae setiform. Ventrosejugal tubercle absent. Pedotectum I represented by small lamina. Discidium present or absent. Anogenital region. With six pairs of genital, one pair of aggenital, two pairs of anal, and three pairs of adanal setae. All setae setiform. Adanal setae $a d_{1}$ posterior, $a d_{2}$ lateral, $a d_{3}$ lateral or anterolateral to anal plate, distance between $a d_{3}-a d_{3}$ longer than $a g-a g$ and $a d_{2}-a d_{2}$. Adanal lyrifissure diagonal, located close to anal aperture. Legs. Setae $l^{\prime \prime}$ and $v^{\prime}$ on tarsus I present. Tarsus II with two solenidia. Juvenile instars. Unknown.

\section{Geminoppia amatholensis sp. $\mathrm{n}$.}

(Figs 1-5)

Diagnosis. Body size: 348-415 × 215-232. Rostrum rounded. Without costula and transcostula. Rostral and lamellar setae of medium length, setiform, barbed. Interlamellar and exobothridial setae short, setiform, thin, slightly barbed. Bothridial seta long, with small head, barbed. Nine pairs of notogastral setae present: $c, h_{2}$ and $p_{1}-p_{3}$ short, setiform, thin, slightly barbed; $l a, l m, l p$, and $h_{1}$ long, setiform, slightly swollen apically, barbed; la located anterior to $l m, h_{2}$ posterolateral to $l p$. Discidium absent.

Description. Measurements. Body length 415 (holotype), 348-415 (seven paratypes); body width 215 (holotype), 215-232 (seven paratypes). No distinct difference between males and females in body size.

Integument (Figs 5A, E). Body color light brown. Body surface microporose (visible only under high magnification in dissected specimens, $\times 1000$ ). Lateral part of rostrum with microfoveolate region. Lateral part of body between bothridium and acetabula I-III partially tuberculate (diameter of tubercle up to 4 ) and microtuberculate (diameter of tubercle less than 1 ).

\footnotetext{
* Data validation of G. papineaui required. On inspection of the holotype of G. ansifera (on permanent loan to NMB), nine pairs of setae including $p_{1}-p_{3}$ were observed and not six ( $p_{1}-p_{3}$ not shown) as in the original description (MAHUNKA 1985b), therefore, it is possible, a similar situation may be with $G$. papineaui ( $p_{1}-p_{3}$ theoretically developed; nine pairs instead six pairs of setae present).
} 
Prodorsum (Figs 1A, 2A, 5A, B). Rostrum rounded. Rostral and lamellar setae (36-41) setiform, barbed. Interlamellar (10-14) and exobothridial (10-12) setae setiform, straight, thin, slightly barbed. Insertion of lamellar seta located closer to insertion of interlamellar seta than to rostral seta. Bothridial seta (86-90) clavate, barbed. Alveolar vestige of second exobothridial seta distinct. Interbothridial region with three pairs of poorly observed muscle sigillae. Interbothridial and postbothridial tubercles not observed. Longitudinal row, comprising several muscle sigillae, present in front of the bothridium.

Notogaster (Figs 1A, 2A, B, 5C, D). Anterior border convex medially, slightly developed. Nine pairs of notogastral setae present $\left(h_{3}\right.$ and their alveolus completely absent): $c$ (6-8), $p_{1}(28-34), h_{2}(16-24)$, and $p_{2^{\prime}} p_{3}(8-10)$ setiform, thin, slightly barbed (visible under high magnification); $l a, l m, l p$, and $h_{1}(114-131)$ setiform, slightly swollen apically, barbed, inserted in two longitudinal, parallel rows. All notogastral lyrifissures, opisthonotal gland opening, circumgastric scissure, and circumgastric sigillar band distinct.

Gnathosoma (Figs 2C-E, 5E). Subcapitulum longer than wide $(77-90 \times 53-61)$. Subcapitular setae setiform, slightly barbed, $a(16-18)$ shorter than $m$ (28-30) and $h(26-28)$. Adoral seta (8-10) setiform, thin, smooth. Palp (53-57) with setation 0-2-1-3-8(+1 solenidion). Sole-

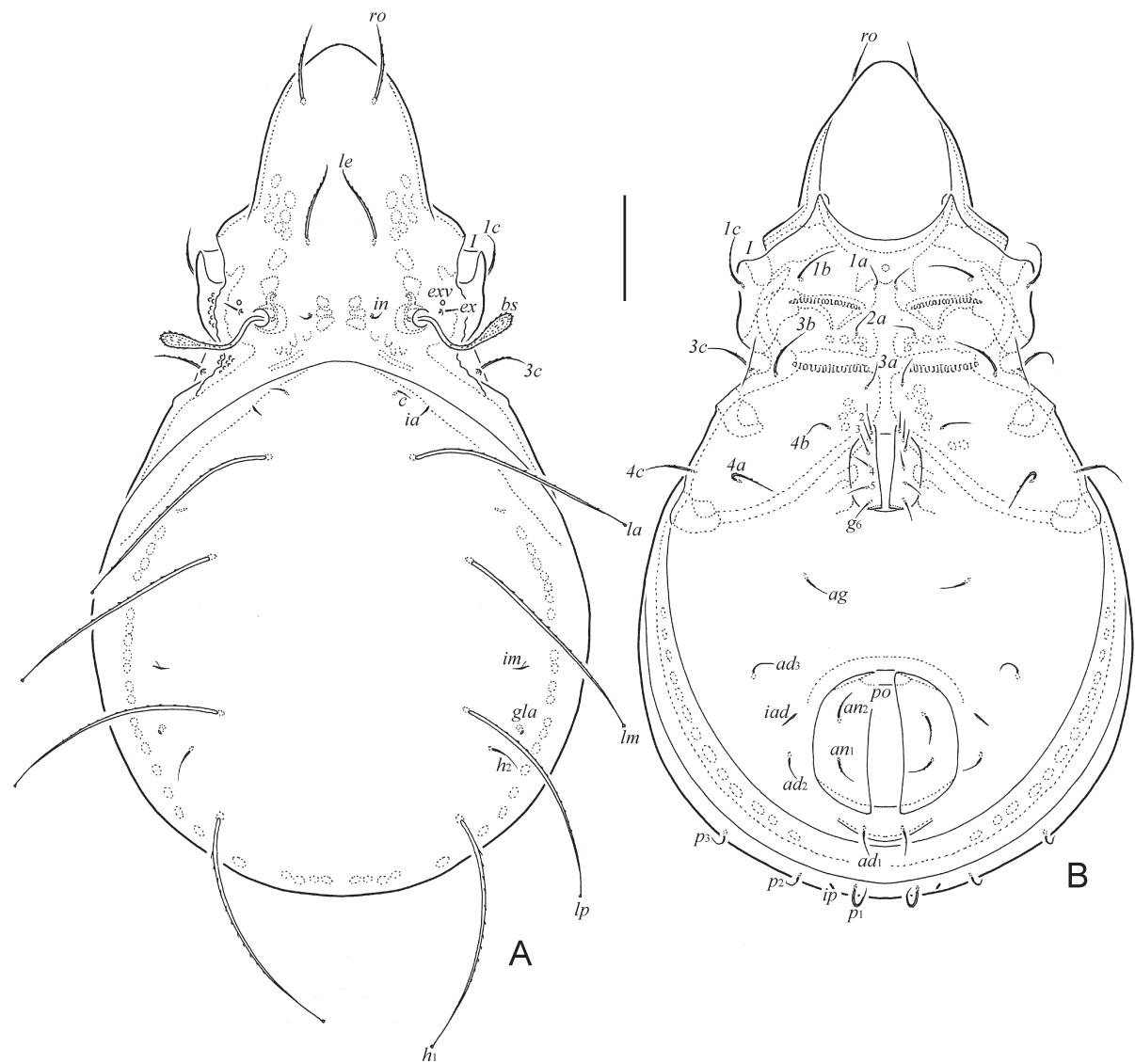

Fig. 1. Geminoppia amatholensis sp. n., adult: $A=$ dorsal view (legs not shown); $B=$ ventral view (gnathosoma and legs not shown). Scale bar: $50 \mu \mathrm{m}$ 
nidion bacilliform, slightly swollen apically and connected with seta $u l^{\prime}$. Postpalpal seta (4) spiniform, smooth. Chelicera (77-90) with two setiform, heavily barbed setae, cha (28-32) thickened, indistinctly swollen apically, chb (16-20) setiform. Trägårdh's organ elongate triangular.

Epimeral and lateral podosomal regions (Figs 1B, 2A, 5F). All epimeral setae $(1 b, 1 c$, $3 b, 3 c$, and $4 a: 36-45 ; 4 c: 28-32 ; 1 a, 2 a, 3 a$, and $4 b: 16-24)$ setiform, slightly barbed. Discidium not developed.

Anogenital region (Figs 1B, 2A, B, 5G, H). Genital seta (10-16), aggenital (16-24), adanal (16-24), and anal (16-24) setae setiform, slightly barbed. Two pairs of genital papillae visible, the first pair not observed. Adanal lyrifissure distinct. Preanal organ caecum-like. Ovipositor elongated $(110 \times 36)$, blade $(41)$ shorter than length of distal section (beyond middle fold; 69). Each of the three blades with four smooth setae, $\psi_{1} \approx \tau_{1}(20)$ setiform, $\psi_{2} \approx$ $\tau \mathrm{a} \approx \tau \mathrm{b} \approx \tau \mathrm{c}(12)$ thorn-like. All coronal setae not observed.

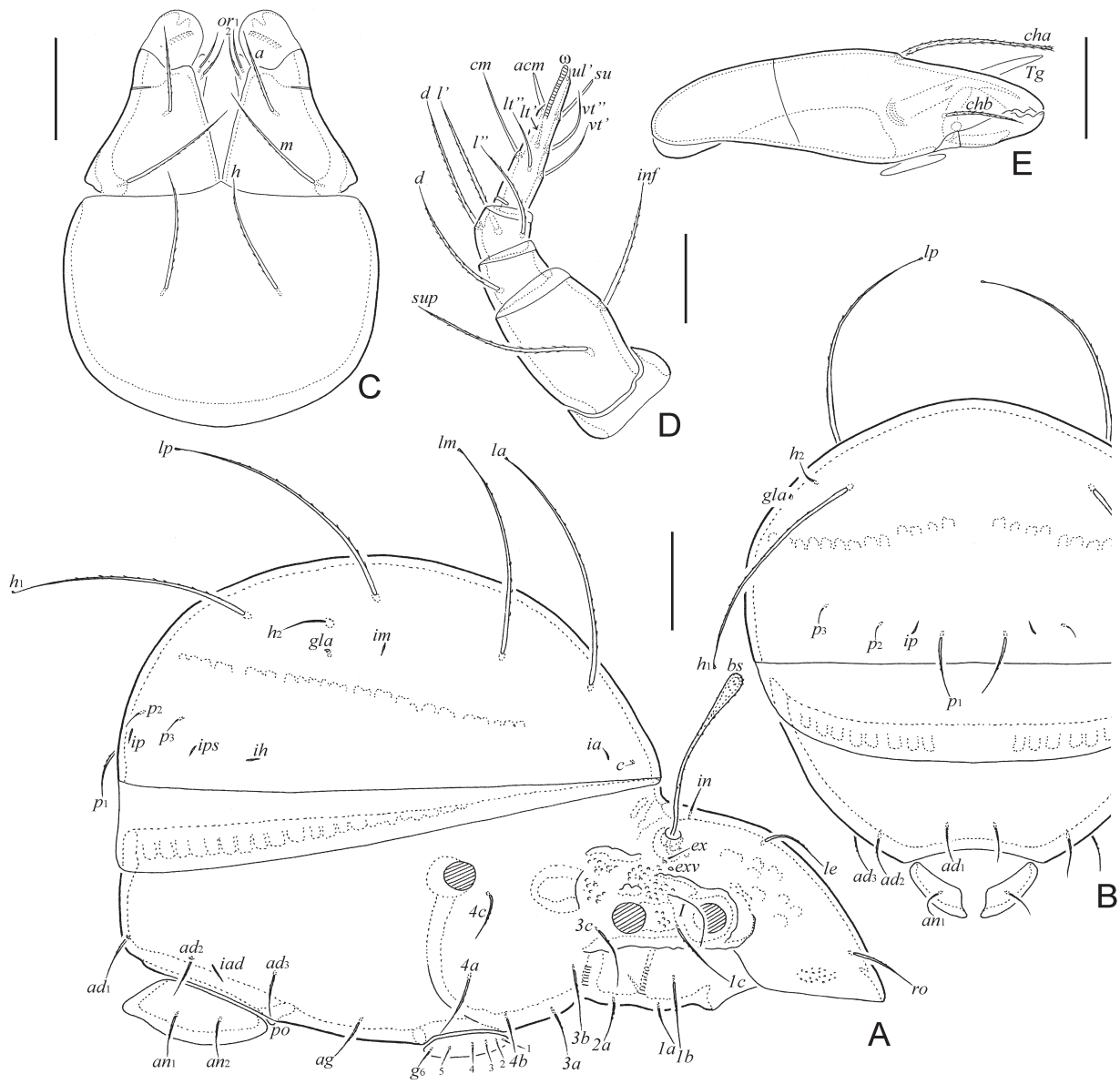

Fig. 2. Geminoppia amatholensis sp. n., adult: $\mathrm{A}=$ lateral view (gnathosoma and legs not shown); $\mathrm{B}=$ posterior view; $\mathrm{C}=$ subcapitulum, ventral view; $\mathrm{D}=$ palp, right, antiaxial view; $\mathrm{E}=$ chelicera, right, antiaxial view. Scale bars: $50 \mu \mathrm{m}(\mathrm{A}, \mathrm{B}), 20 \mu \mathrm{m}(\mathrm{C}, \mathrm{E}), 10 \mu \mathrm{m}(\mathrm{D})$ 
Leg (Figs 3A, B, 4A, B). Leg claw slightly barbed on dorsal side. Trochanter III with one or two small teeth posteriorly. Porose area on all femora well visible, but not observed on trochanters. Formulas of leg setation and solenidia: I (1-5-2-4-20) [1-2-2], II (1-5-2-4-16) [1-1-2], III (2-3-1-3-15) [1-1-0], IV (1-2-2-3-12) [0-1-0]; homology of setae and solenidia indicated in Table 1 . Setae $p$ setiform on tarsi I, and very short, conical on tarsi II-IV. Famulus of tarsus I minute, erect, slightly swollen apically, inserted posterior to $\omega_{1}$. Solenidia $\omega_{1}$ on tarsi I, $\omega_{1}$ and $\omega_{2}$ on tarsi II and $\sigma$ on genua III slightly bacilliform, other solenidia setiform, slightly swollen apically.

Material examined. Holotype (male) and seven paratypes (three males and four females): South Africa, Amathole mountains in the Eastern Cape Province, Hogsback State Forest at the village of Hogsback, 32 $35^{\prime} 21.6^{\prime \prime} \mathrm{S}, 26^{\circ} 57^{\prime} 38.5^{\prime \prime} \mathrm{E}$, indigenous Afromontane mixed forest (Mucina \& Geldenhuys 2006), consisting of tall trees (dominant species, e.g. Afrocarpus falcatus (yellowwood), Celtis africana (white stinkwood), Calodendrum capense

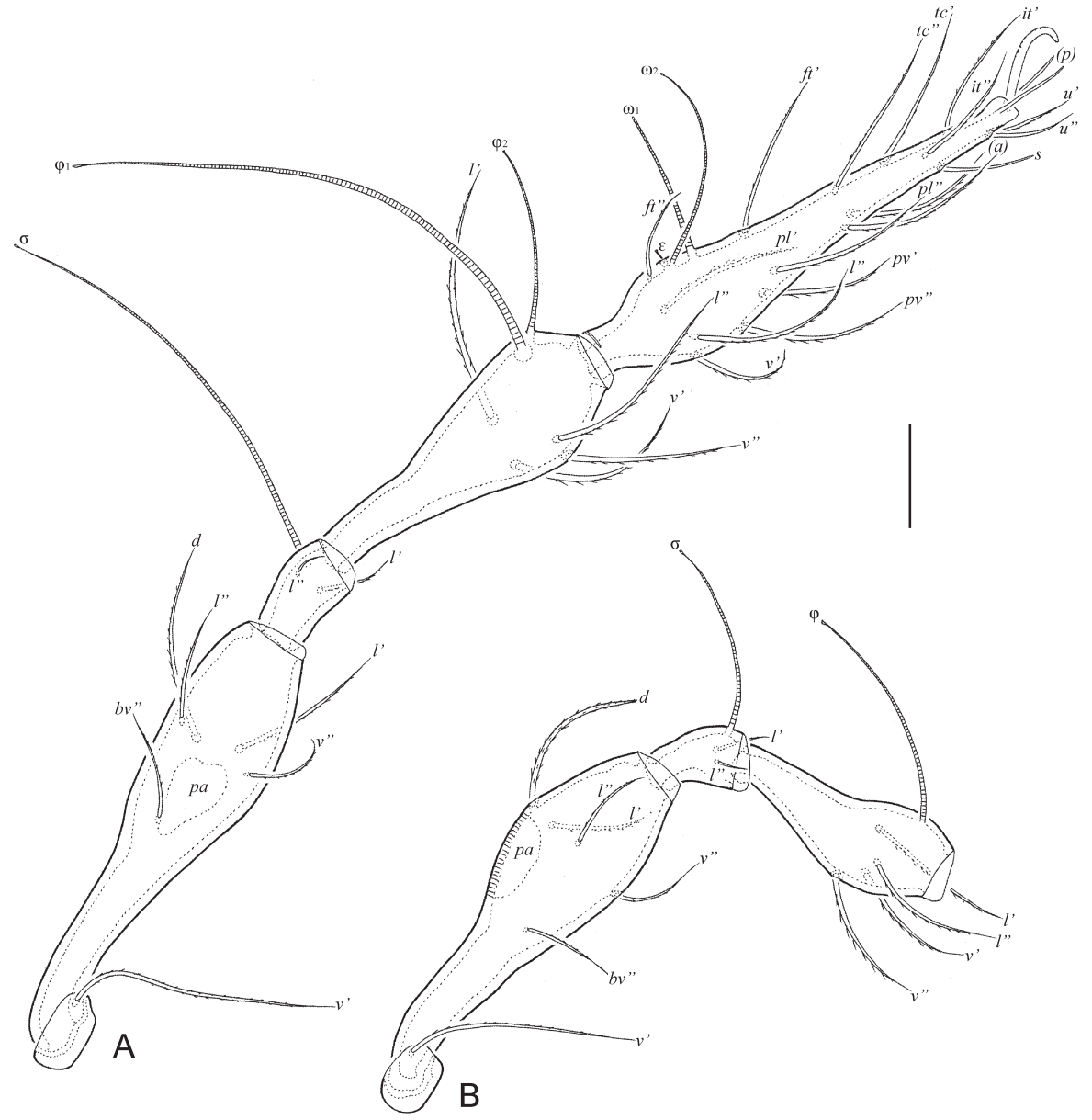

Fig. 3. Geminoppia amatholensis sp. n., adult: A = leg I, right, antiaxial view; B = leg II, without tarsus, right, antiaxial view. Scale bar: $20 \mu \mathrm{m}$ 
(Cape chestnut) and Vepris lanceolata (white ironwood)) and a dense understorey of shrubs, herbs and moss, in moss on unknown tree, 14.IX.2019 (collected by V. A. Khaustov, S. G. Ermilov, E. A. Hugo-Coetzee, and A. A. Khaustov).

Type deposition. The holotype (male) is deposited in the collection of the National Museum Bloemfontein, South Africa (NMB); seven paratypes (three males and four females) are deposited in the collection of the Tyumen State University Museum of Zoology, Tyumen, Russia (TSUMZ). All specimens are preserved in $70 \%$ solution of ethanol with a drop of glycerol.

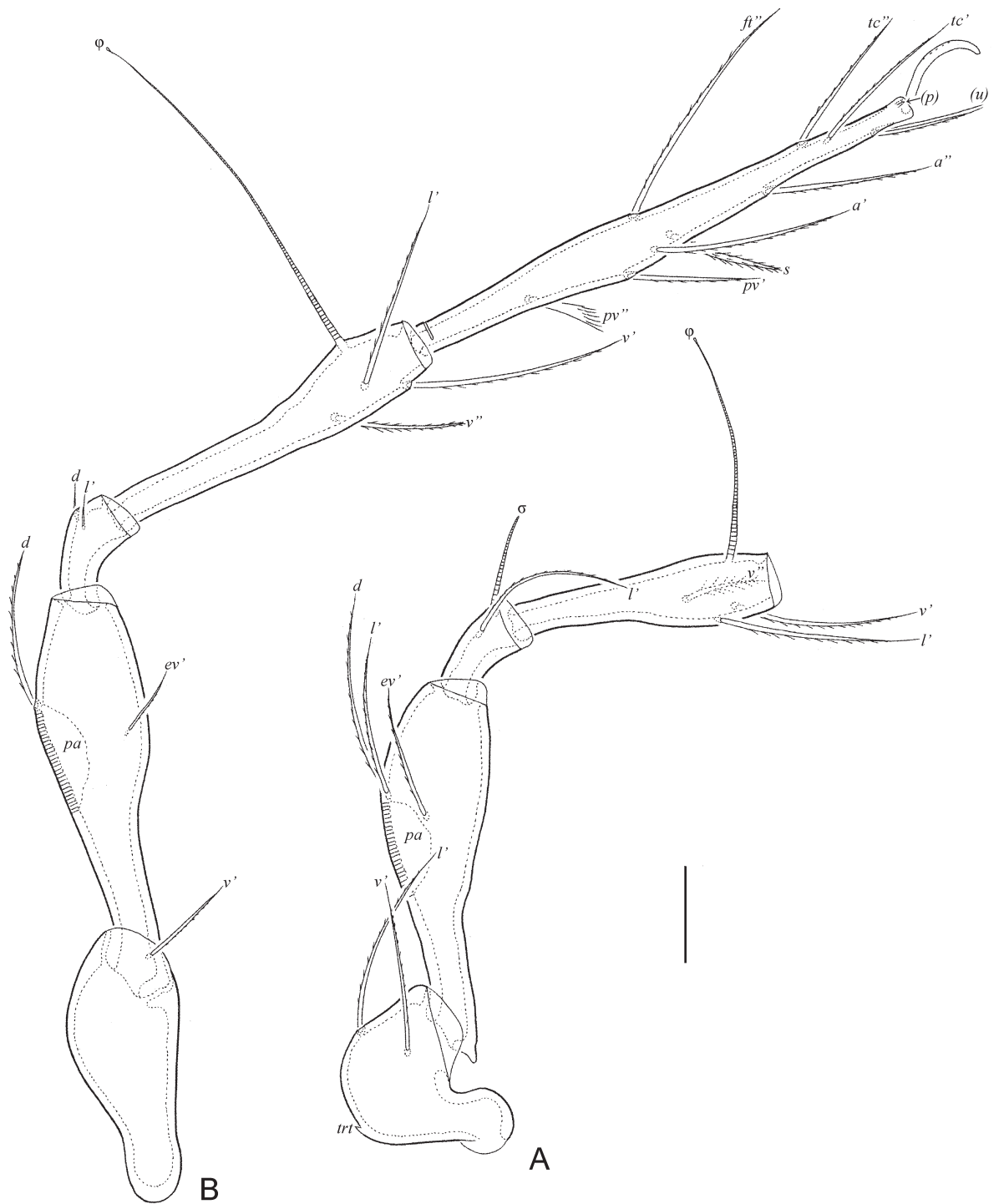

Fig. 4. Geminoppia amatholensis sp. n., adult: $\mathrm{A}=$ leg III, without tarsus, left, antiaxial view; $\mathrm{B}=$ leg IV, left, antiaxial view. Scale bar: $20 \mu \mathrm{m}$ 
Etymology. The specific name amatholensis refers to the Amathole mountains, where the new species was collected.
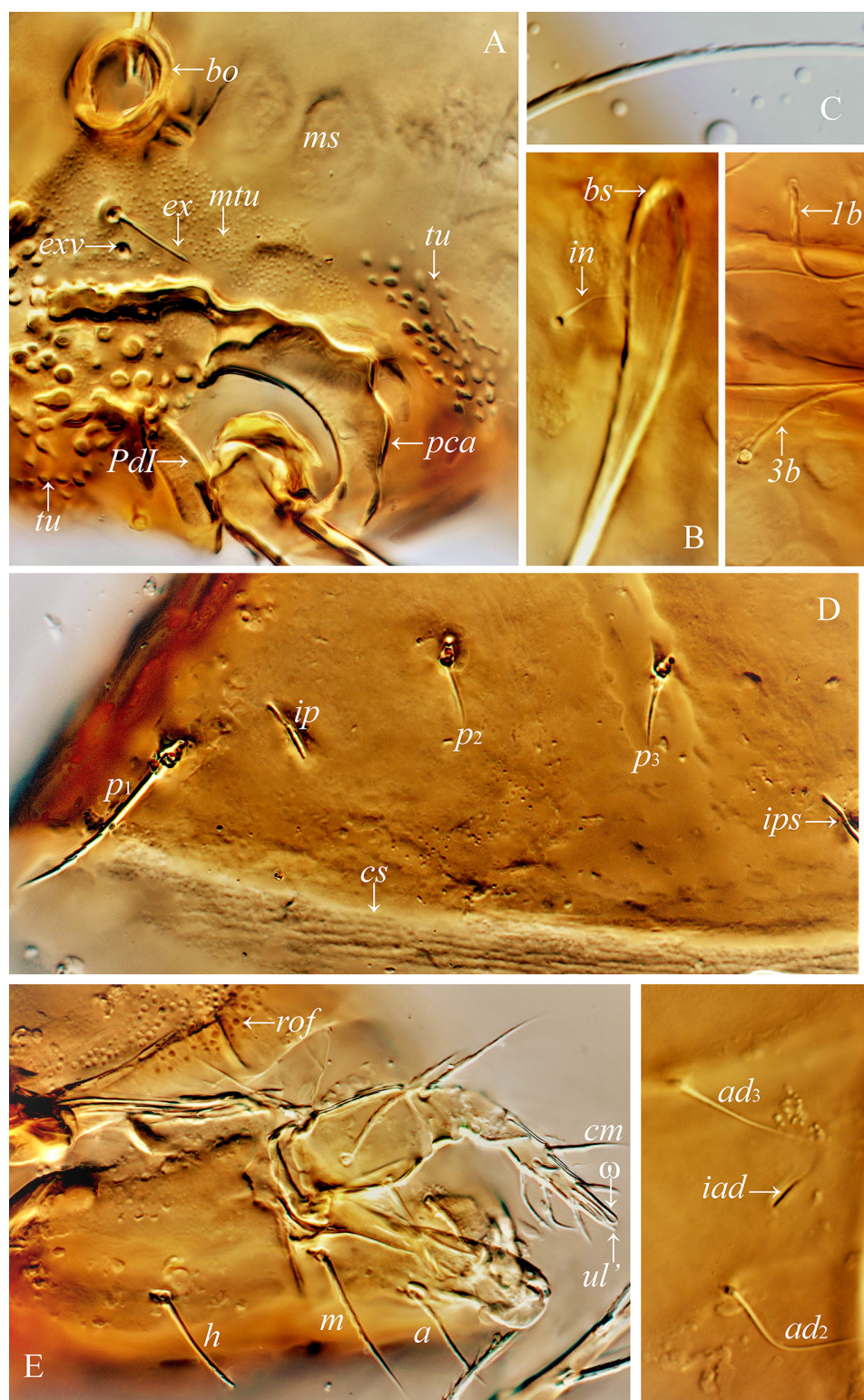
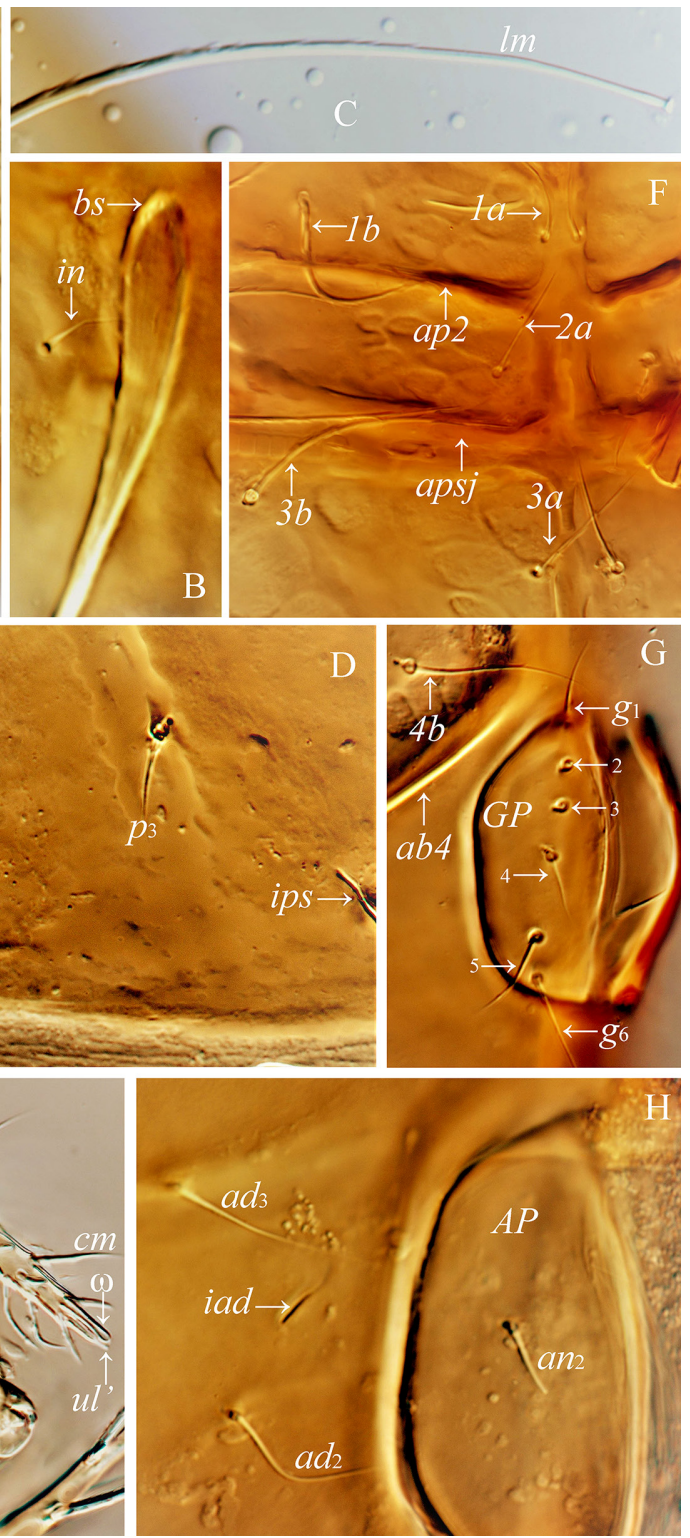

Fig. 5. Geminoppia amatholensis sp. n., dissected adult, microscope images (magnification 1000): $\mathrm{A}=$ part of lateral side of prodorsum; $\mathrm{B}=$ bothridial head; $\mathrm{C}=$ mediodistal part of notogastral seta $l m ; \mathrm{D}=$ part of lateral side of notogaster; $\mathrm{E}=$ gnathosoma, lateral view; $\mathrm{F}=$ part of epimeral region; $\mathrm{G}=$ genital plates; $\mathrm{H}=$ part of anoadanal region 
Table 1. Leg setation and solenidia of adult Geminoppia amatholensis sp. $\mathbf{n}$.

\begin{tabular}{lccccc}
\hline Leg & Tr & $F e$ & $G e$ & $T i$ & $T a$ \\
\hline I & $v^{\prime}$ & $d,(l), b v^{\prime \prime}, v^{\prime \prime}$ & $(l), \sigma$ & $(l),(v), \phi_{1}, \phi_{2}$ & $(f t),(t c),(i t),(p),(u),(a), s,(p v), v^{\prime},(p l)$, \\
II & $v^{\prime}$ & $d,(l), b v^{\prime \prime}, v^{\prime \prime}$ & $(l), \sigma$ & $(l),(v), \phi$ & $(f t),(t c),(i t),(p),(u),(a), s,(p v), l^{\prime \prime}, \omega_{1^{\prime}} \omega_{2}$ \\
III & $l^{\prime}, v^{\prime}$ & $d, l^{\prime}, e v^{\prime}$ & $l^{\prime}, \sigma$ & $l^{\prime},(v), \phi$ & $(f t),(t c),(i t),(p),(u),(a), s,(p v)$ \\
IV & $v^{\prime}$ & $d, e v^{\prime}$ & $d, l^{\prime}$ & $l^{\prime},(v), \phi$ & $f t^{\prime \prime},(t c),(p),(u),(a), s,(p v)$ \\
\hline
\end{tabular}

Roman letters refer to normal setae, Greek letters to solenidia (except $\varepsilon=$ famulus). Single quotation mark (') marks setae on the anterior and double quotation mark (") setae on the posterior side of a given leg segment. Parentheses refer to a pair of setae.

Remarks. Distinctive characters of the new species with the other species of the genus Geminoppia can be found in the identification key below.

\section{TAXONOMIC NOTES}

Globoppia maior was described by Hammer (1962a) and tentatively included in Globoppia. However, this species differs from other representatives of the genus by the absence of notogastral seta $h_{3}$ (reduced number of notogastral setae) versus this seta always present (no reduction of number of notogastral setae) in Globoppia (generic characteristic). All morphological traits of G. maior correspond to those of the genus Geminoppia (see diagnosis above), therefore we propose the following combination: Geminoppia maior (Hammer, 1962) comb. n.

Geminoppia is very similar to the related genera Basiloppia Balogh, 1983 and Globoppia Hammer, 1962. The genus Basiloppia was described by BALOGH (1983) with Oppia hexatricha Balogh et Mahunka, 1975 as type species. This monotypic genus is very similar to Geminoppia differing only by the presence of five pairs of genital setae (versus six pairs). The genital setation is an important generic/subgeneric trait in Oppiidae. However, the reduction in the number of notogastral setae in Geminoppia and Basiloppia (rare in the family) can theoretically serve as a reason for merging these genera despite different numbers of genital setae. The genus Globoppia was described by HaMMER (1962a) with Globoppia intermedia Hammer, 1962 as type species. It is very similar to Geminoppia differing only by the lack of reduction in the number of notogastral setae, i.e. all setae of $h$-row developed (versus one seta of $h$ row completely absent). On the one hand, the number of notogastral setae may be used in distinguishing genera, but on the other hand, accumulated morphological data show that some oppiid genera may include species with different numbers of notogastral setae (e.g. Lasiobelba Aoki, 1959; for example, L. camerunica Ermilov et Starý, 2018 and L. tsaoshanensis Ermilov, 2018 have reduced number of notogastral setae due to lack of $h_{3}$ (see Ermilov \& LiaO 2018, ERmilov \& Starý 2018) versus all notogastral setae developed in the 
other species). Therefore, a reduction of notogastral setae in Geminoppia can theoretically serve as a reason for uniting this genus with Globoppia. Thus, to clarify the relationship of the genera Geminoppia, Basiloppia and Globoppia, further studies, possibly genetic studies are needed.

\section{Key to known species of Geminoppia}

1 Rostrum tripartite; body length: 328-352 m. Distribution: South Africa.

$$
\text { G. ansifera (Mahunka, 1985b) }
$$

- $\quad$ Rostrum rounded

2 Notogastral seta la inserted distinctly anterolateral to $\mathrm{lm}$; body length: 394 . Distribution: New Caledonia. G. papineaui J. Balogh et P. Balogh, 1983

- Notogastral seta la inserted anteriorly to $\mathrm{lm}$

3 Costula and transcostula present; dorsal notogastral setae $l a, l m$ and $l p$ of medium length; body length: 480. Distribution: Brazil.

$$
\text { G. velata (Franklin et Woas, 1992) }
$$

- Costula and transcostula absent; dorsal notogastral setae $l a, l m$ and $l p$ very long

4 Discidium present; notogastral seta $h_{1}$ minute, distinctly shorter than $h_{2}$ and $p_{1}$; body length: 620. Distribution: Sub-Antarctic and southern Neotropical regions.

G. maior (Hammer, 1962)

- Discidium absent; notogastral seta $h_{1}$ very long, distinctly longer than $h_{2}$ and $p_{1}$; body length: 348-415. Distribution: South Africa.

G. amatholensis sp. n.

\section{Distribution and habitat of Geminoppia}

Individuals of the genus Geminoppia seem to prefer moist habitats. Geminoppia amatholensis sp. $\mathbf{n}$. was sampled from moist moss in an indigenous Afromontane forest in South Africa (see details in the 'Material examined' section as well as Mucina \& Geldenhuys 2006). The other South African species, G. ansifera, was sampled from mountain fynbos in the Dwarsberge (sample E-Y No 253 as indicated in MAHUnKa 1985a), today situated in the Hottentos Holland Nature Reserve, an area with an annual rainfall of up to $3300 \mathrm{~mm}$ (www.capenature.co.za/reserves/hottentots-holland-nature-reserve).

The type species, G. papineaui was sampled in primary rainforest, leaf litter and soil around the base of a tree in New Caledonia (BAlogh \& BALOGH 1983). Geminoppia velata seems to be abundant in primary and semi-deciduous 
forests in the Brazilian states of Amazonia and Pará (Franklin \& Woas 1992, Franklin et al. 2006, Ferreira et al. 2012, Oliveira et al. 2017).

Geminoppia maior is distributed in the southern Neotropical and sub-Antarctic regions (SubÍAs 2020). It was originally described from specimens found in litter of Ranunculus, Hieracium, Rumex, Holcus and other grasses under bramble, Berberis and tall trees and in very wet moss on stones close to Port Montt as well as wet moss close to Punta Arenas, southern Chile (HAmmer 1962a). It has also been recorded from the litter of a sub-Antarctic Nothofagus forest, on Mount Susana, Patagonia, Argentina (Mahunka 1980), in slightly moist moss on a tree in the forest close to the Perito Moreno Glacier, Patagonia, Argentina (Hammer 1962b), from peat, tussock and Apium australe litter on Beauchene Island of the Falkland Island group (STARÝ 1995), unburned Empetrum rubrum heath on West Falkland (STARÝ \& Block 1996) and from Araucaria araucanal Nothofagus pumilio trees near the Icalma Lake in the La Araucania Region of Chile (Martínez \& Casanuena 1995).

Acknowledgements - The authors thank Vladimir A. Khaustov (Tyumen State University, Tyumen, Russia) and Jan Andries Neethling (National Museum, South Africa) for helping with fieldwork; and the two anonymous reviewers for their valuable comments. Permission to sample in Hogsback State Forest was granted by the Department of Agriculture, Forestry and Fisheries (DAFF). The study was funded by the Russian Foundation for Basic Research according to the research project № 18-04-00096A.

\section{REFERENCES}

AокI, J. (1959): Die Moosmilben (Oribatei) aus Südjapan. - Bulletin of the Biogeographical Society of Japan 21: 1-22.

BAlogh, J. (1983): A partial revision of the Oppiidae Grandjean, 1954 (Acari: Oribatei). Acta Zoologica Academiae Scientiarum Hungaricae 29: 1-79.

Balogh, J. \& BAlogh, P. (1983): New oribatids (Acari) from the Pacific region. - Acta Zoologica Academiae Scientiarum Hungaricae 29: 303-325.

Balogh, J. \& Mahunka, S. (1975): New oppioid mites (Acari: Oribatei) from Queensland. Acta Zoologica Academiae Scientiarum Hungaricae 21: 241-256.

Ermilov, S. G. \& Liao, J.-R. (2018): A new species of Lasiobelba (Acari, Oribatida, Oppiidae) from Taiwan. - Acarina 26: 81-87. https://doi.org/10.21684/0132-8077-2018-26-1-81-87

Ermilov, S. G. \& Starý, J. (2018): Oribatid mites (Acari, Oribatida) from Korup National Park (Cameroon): list of taxa, new findings, descriptions of two new species. - Systematic and Applied Acarology 23: 733-747. https://doi.org/10.11158/saa.23.4.12

Ferreira, R. N. C., Franklin, E., De Souza, J. L. P. \& De Moraes, J. (2012): Soil oribatid mite (Acari: Oribatida) diversity and composition in semi-deciduous forest fragments in eastern Amazonia and comparison with the surrounding savanna matrix. - Journal of Natural History 46: 2131-2144. https://doi.org/10.1080/00222933.2012.707245 
Franklin, E., Santos, E. M. R. \& Albuquerque, M. I. C. (2006): Diversity and distribution of oribatid mites (Acari: Oribatida) in a lowland rain forest in Peru and in several environments of the Brazilians states of Amazonas, Rondônia, Roraima and Pará. - Brazilian Journal of Biology 66: 999-1020. https://doi.org/10.1590/S1519-69842006000600007

Franklin, E. \& Woas, S. (1992): Some oribatid mites of the family Oppiidae (Acari, Oribatei) from Amazonia. - Andrias 9: 5-56.

Hammer, M. (1962a): Investigations on the oribatid fauna of the Andes Mountains. III. Chile. - Det Kongelige Danske Videnskabernes Selskab Biologiske Skrifter 13(2): 1-96.

Hammer, M. (1962b): Investigations on the oribatid fauna of the Andes Mountains. IV. Patagonia. - Det Kongelige Danske Videnskarbernes Selskab Biologiske Skrifter 13: 1-34.

MahunKa, S. (1980): Neue und interessante Milben aus dem Genfer Museum XXXIII. Oribatids (Acari) from Monte Susana. (Tierra del Fuego, Argentina). - Revue Suisse Zoologie 87: 155-181. https://doi.org/10.5962/bhl.part.85513

Mahunka, S. (1985a): Oribatids from Africa (Acari: Oribatida) I. - Acta Zoologica Hungarica 31: 295-339.

Mahunka, S. (1985b): Oribatids from Africa (Acari: Oribatida) II. - Folia entomologica hungarica 46: 73-113.

Martínez, R. I. \& Casanuena, M. E. (1995): Comparacion cuali-cuantitativa de la fauna oribatologica de suelo (Acari: Oribatida) de bosques nativos y Pinus radiata. - Revista Chilena de Entomología 22: 25-34.

Mucina, L. \& Geldenhuys, C.J. (2006): Afrotemperate, subtropical and azonal forests. Pp. 585-615. In: Mucina, L. \& Rutherford, M. C. (eds): The vegetation of South Africa, Lesotho and Swaziland. Strelitzia 19. South African National Biodiversity Institute, Pretoria.

Norton, R. A. (1977): A review of F. Grandjean's system of leg chaetotaxy in the Oribatei (Acari) and its application to the family Damaeidae. Pp. 33-61. In: DindaL, D. L. (ed.): Biology of oribatid mites. - SUNY College of Environmental Science and Forestry, Syracuse.

Norton, R. A. \& Behan-Pelletier, V. M. (2009): Suborder Oribatida. Chapter 15. Pp. 430564. In: Krantz, G. W. \& Walter, D. E. (eds): A manual of acarology. - Texas Tech University Press, Lubbock.

Oliveira, A. R., Argolo, P. S., De Moraes, G. J., Norton, R. A. \& Schatz, H. (2017): A checklist of the oribatid mites species (Acari, Oribatida) of Brazil. - Zootaxa 4245: 001-089. https://doi.org/10.11646/zootaxa.4245.1.1

StARÝ, J. (1995): Oribatid mites (Acari: Oribatida) of Beauchene Islands, Falklands, South Atlantic. - Journal of Natural History 29: 1461-1467. https://doi.org/10.1080/00222939500770621

Starý, J. \& Block, W. (1996): Oribatid mites (Acari: Oribatida) of the Falkland Islands, South Atlantic and their zoogeographical relationships. - Journal of Natural History 30: 523-535. https://doi.org/10.1080/00222939600770281

Subías, L. S. (2004): Listado sistemático, sinonímico y biogeográfico de los ácaros oribátidos (Acariformes, Oribatida) del mundo (1758-2002). - Graellsia 60 (número extraordinario): 3-305. https://doi.org/10.3989/graellsia.2004.v60.iExtra.218

Subías, L. S. (2020): Listado sistemático, sinonímico y biogeográfico de los ácaros oribátidos (Acariformes: Oribatida) del mundo (excepto fósiles). $527 \mathrm{pp}$. [online version accessed in January 2020]

Subías, L. S. \& BAlogh, P. (1989): Identification keys to the genera of Oppiidae Grandjean, 1951 (Acari: Oribatei). - Acta Zoologica Hungarica 35: 355-412.

Travé, J. \& Vachon, M. (1975): François Grandjean. 1882-1975 (Notice biographique et bibliographique). - Acarologia 17: 1-19.

Received November 10, 2020, accepted January 9, 2021, published August 16, 2021 